\title{
Media communication activities of Russian universities: Dynamics of the development and evaluation of social network efficiency
}

\author{
Anna Gureeva ${ }^{1}$ \\ Elina Samorodova \\ Vasilisa Kuznetsova \\ Lomonosov Moscow State University, Russia
}

DOI: 10.30547/worldofmedia.1.2020.2

\begin{abstract}
Social networks are now one of the most popular communication channels, occupying the most important position in the modern media system. Universities as centres of science and education, trying to meet modern standards of media promotion, actively use social networks as a platform for communication with all their many target audiences, with young people as the foundation. The study aims to analyze media communication activities of Russian universities in social networks and to identify the main features of their practices: which social network is most actively used, where media communication activities are more effective and which universities are more involved in media promotion. This article presents the results of the study of the activity of official accounts in social networks of three leading universities in Russia for the period 2017-2020. The data obtained show that the most widespread social network is Vkontakte. However, the number of subscribers and the number of daily publications in the account do not always increase the efficiency of communications - qualitative parameters prevail over quantitative ones in evaluating the efficiency of universities' media communication activities in social networks. The active presence and response of subscribers are most clearly reflected by such an indicator as audience involvement, and the users are most actively involved in the Instagram social network.
\end{abstract}

${ }^{1}$ Corresponding author:

Anna Gureeva, Lomonosov Moscow State University, Faculty of Journalism, 9, Mokhovaya st, Moscow, Russia.

Email: gureevaan@gmail.com 


\section{Keywords}

Media communications, universities, social media, content, engagement rate.

\section{Introduction}

Modern society is increasingly dependent on information and communication technologies and digital media - virtually no social sphere exists outside the context of mediatization. The influence of media in science and education is also becoming stronger. As a result, communication activities required by universities and scientific organizations to increase interest in their work, attract funding, and maintain their image are significantly transformed (Bukki \& Trench, 2018).

Due to the general digitalization of the media space, the Internet, in particular social networks, is now the most significant part of the media consumption structure. The Russian Internet today as a communication platform is the core of the Russian media system (Vartanova, 2001, 2015; Vartanova \& Gladkova, 2019). According to Mediascope research company, the monthly Internet audience in Russia reached 95.8 million people by November $2019^{2}$. The penetration of social networks in Russia is estimated at $49 \%$ and 70 million citizens have accounts in them ${ }^{3}$. The most popular social networks in Russia are Vkontakte and Instagram ${ }^{4}$. Thus, as one of the most popular communication channels for the target audience, social networks require close examination (Lukina, 2011).

Social networks play a special role in the corporate communications system of the Russian higher school because of the peculiarities of youth media consumption (Gorokhov, 2006). Besides, online media opportunities create a wide range of highly effective communications for higher education institutions (Gureeva et al., 2018). At the same time, the most active segment of the social media audience is students whose personality formation takes place in the context of intensive intellectual development, which, of course, is facilitated by studying at universities (Dunas et al., 2017). The specifics of modern media consumption and the challenges faced by Russian higher education institutions actualize the need to use all possible means of media communications (Gureeva, 2017). The demand for social networks for media communications activities of universities is obvious: today almost all Russian universities have official accounts in the most popular social networks (Gorokhov et al., 2018).

\footnotetext{
${ }^{2}$ Available from: https://webindex.mediascope.net/general-audience

${ }^{3}$ Available from: https://globlee.ru

${ }^{4}$ Available from: https://br-analytics.ru/blog/social-media-russia-2019/
} 
However, the boundaries of the media communication system are constantly expanding, both in terms of the amount of digital content available and the increasing duration of media consumption. Whereas researchers used to divide media communications into traditional and digital, it is no longer possible to draw a clear line between these categories. Under these conditions, the need to constantly rethink the system of interrelationships between the scientific and educational sphere and the media space is becoming more and more urgent (Vartanova, 2017).

In this connection, a study of media communication activities of Russian universities in social networks has been conducted. The aim was to analyze the dynamics of media promotion of official accounts in social networks of three leading Russian universities from 2017 to 2020 . The objectives of the study also included identification of the main features of media communication practices of universities in social networks: which social network is most actively used and has the largest audience, in which social network media communication activity is more effective, whether the involvement of the audience is determined by the daily frequency of publications on the page and the number of subscribers, and if so, what is the dependence between them.

Since successful media promotion seems to be an important component of universities' competitiveness, the research subject was the accounts in social networks of three leading Russian universities according to QS ranking for 2020: Lomonosov Moscow State University, St. Petersburg State University and Novosibirsk State University. The rankings give a clear picture of the prestige and quality of an educational institution (Hazelkorn, 2011; van Vught, 2008), while QS is one of the most cited rankings in the world, evaluating universities on a wide range of issues of interest to potential students: research, teaching, employment and internationalization ${ }^{5}$. Media communication activities were analyzed in the most popular social networks among young people in Russia according to Mediascope $^{6}$, which are Vkontakte, Facebook and Instagram. Odnoklassniki social network was not analyzed, because the age of its active audience is from 25 years old ${ }^{7}$ that does not exactly match the target audience of universities.

${ }^{5}$ Available from: https://www.topuniversities.com/qs-world-university-rankings/methodology

6 Available from: https://mediascope.net/upload/iblock/f97/18.04.2019_ Mediascope_\%D0\%95\%D0\%BA\%D0\%B0\%D1\%82\%D0\%B5\%D1\%80\%D0 \%B 8\%D0\%BD\%D0\%B0\%20\%D0\%9A\%D1\%83\%D1\%80\%D0\%BD\%D0\%B E\%D1\%81\%D0\%BE\%D0\%B2\%D0\%B0_\%D0\%A0\%D0\%98\%D0\%A4+\%D0\%9A\%D0\%98\%D0\%91\%202019.pdf

${ }^{7}$ Available from: https://hiconversion.ru/blog/auditoriya-socialnyh-setej-runeta-gde-kto-zaputalsya/ 
Quantitative research of the accounts of the top 3 Russian universities allowed to reveal the total audience of the official accounts of the universities in social networks, as well as to track the data dynamics within the media promotion from 2017 to 2020 . A comparative analysis was used to identify the main features of media communication practices. Also, in each study period, an average engagement rate (ER) was calculated, which allowed to evaluate the effectiveness of social networks of the universities and to track the dynamics of media promotion in social networks over 4 years. Engagement is both a goal and a means for users to interact with online media (Napoli, 2014). That is why many researchers study engagement rate as an indicator of audience activity (Lagun \& Lalmas, 2016; Mersey et al., 2010; O’Brien \& Toms, 2008).

Engagement rate is a key qualitative indicator of social networking success (Niciporuc, 2014), which is displayed by the number of user interactions with the post or profile (likes, reposting, comments, clicking on a link), divided by the total number of subscribers of the page, multiplied by $100 \%$. The indicator less than $1 \%$ is considered low, from $1 \%$ to $3 \%$ - medium, from $3 \%$ to $6 \%$ high, over $6 \%$ - very high. Among the characteristics that influence audience engagement, researchers note the context, content and identity of the author (Jaakonmäki et al., 2017).

\section{Media communication practices of leading Russian universities on social networks}

The study recorded the total audience of official university accounts in social networks in February 2017, May 2018, May 2019, January 2020. The results presented in Table 1 show a consistent growth of subscribers at all three universities over the 4 years. This is a clear sign that these universities are actively involved in the communication space of social networks, demonstrating a rapid response to changes in media consumption. 
Table 1

\section{Total audience of social media accounts of top 3 universities in Russia (VK, Facebook, Instagram)}



The highest figure of total audience coverage over the whole period under study is in social networks at Moscow State University (MSU). However, if we analyze the annual growth in the number of subscribers as a percentage, the strongest dynamics of audience growth will be in social networks of St. Petersburg State University. Over the four years from 2017 to 2020, the audience of accounts of this university increased by $25 \%$ on average, while the number of subscribers to social networks at MSU increased by $22 \%$ annually. The audience growth dynamics at Novosibirsk State University's social networks is significantly lower: the indicators have increased on average by $9 \%$ each year.

It could be assumed that the annual growth of the social media audience can be explained by the annual influx of new students to the university, as well as applicants interested in studying and their parents. In this case, the difference in the number of subscribers may be determined by the size of the university.

For example, the ratio of the total audience of social networks of universities to the number of students in an educational institution can be analyzed. Thus, for 2020 the approximate number of students in the studied universities is 40 thousand at MSU, 30 thousand at St. Petersburg State University, 8 thousand 
at Novosibirsk State University (NSU). Comparing these figures with the total audience of social networks, we can see that the more students in an educational institution, the more its coverage in social networks: both in terms of the number of students and number of subscribers the MSU is leading.

However, calculating the percentage of the audience of the accounts in social networks to the number of students, it will be seen that the largest indicator will be at NSU, whose audience in social networks relative to the number of students is $368 \%$. The MSU indicator is $302 \%$, while that of St. Petersburg State University is $216 \%$. This may imply that the accounts of NSU in social networks VKontakte, Facebook and Instagram are more popular among its target audience than the accounts of MSU and St. Petersburg State University.

\section{Vkontakte}

To assess the effectiveness of the universities' media communication activities, an average post engagement rate was calculated for each period under study. All reactions to the post were divided by the number of subscribers and multiplied by $100 \%$, after which the average monthly indicator was calculated. The results for the VKontakte social network are presented in Table 2.

Table 2

The average engagement rate per post on VK in \%

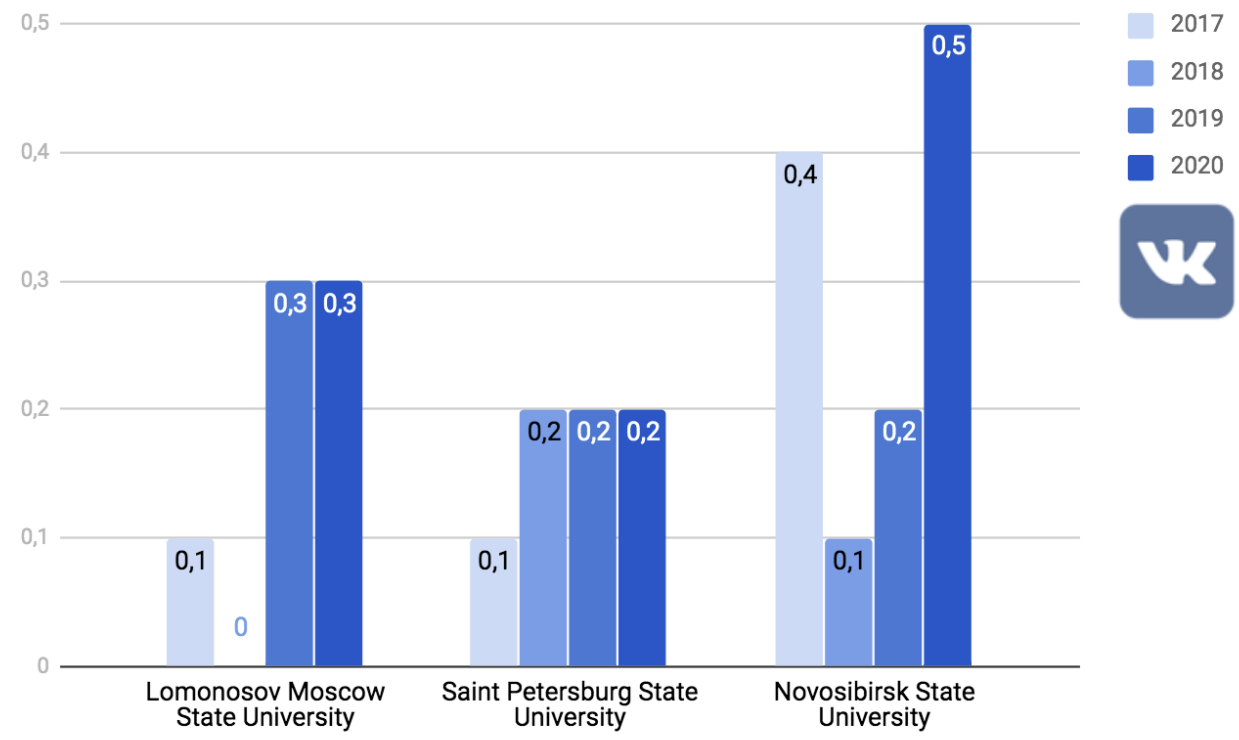


The chart shows that the maximum level of audience involvement in the social network Vkontakte is fixed at NSU $-0.5 \%$ in 2020. Moreover, the indicators are quite chaotic: relatively high in $2017(0.4 \%)$ and in $2020(0.5 \%)$ and lower in $2018(0.1 \%)$ and 2019 (0.2\%). Figures of MSU and St. Petersburg State University are more stable with consistent dynamics ranging from $0.1 \%$ to $0.3 \%$, although with a failure on the page of MSU in 2018 when the value was equal to 0 . However, it should be noted that the engagement rate of all the studied universities in all periods are low on generally accepted measures of ER - less than 1\%.

To analyze the specifics of universities' media communication activity in social networks, the average daily frequency of publications in each studied period was estimated. The data on the Vkontakte social network are presented in Table 3.

Publications on the official page of MSU were made most often - 5,8 per day in 2017. In St. Petersburg State University, the maximum indicator was also fixed in $2017-4,5$ per day. Daily posts in the account of NSU were made less often $-0,5$ per day or 1 publication for two days in 2020. Thus, it could be noted that there are no certain trends in the frequency of publications. This may mean that universities in their media communication activities do not pay attention to the number of daily posts, not adhering to certain rules regarding the frequency of posts.

Table 3

The average daily frequency of publications on VK

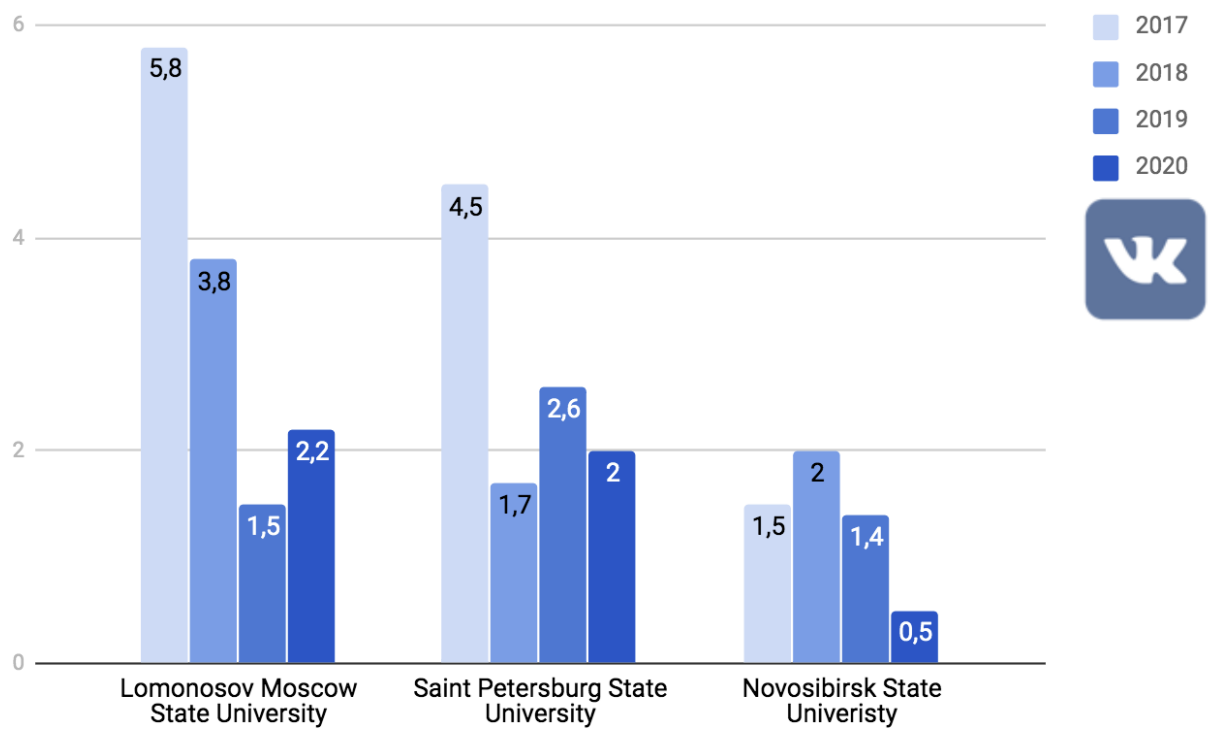


By comparing the frequency of publications with the engagement rate calculated earlier, some correlation between these data could be observed. For instance, the NSU's highest engagement rate among the universities studied $(0.5 \%$ in 2020) corresponds to the lowest frequency of publications in this period (0.5). At the same time, the lowest ER fixed on the NSU's page in 2018 corresponds to the highest frequency of publications during the study periods (2). The lowest ER in the Vkontakte account of St. Petersburg State University (0.1\% in 2017) similarly corresponds to the highest frequency of publications for 4 years (4.5). In MSU Vkontakte account the highest frequency (5.8 in 2017) corresponds not to the lowest $\mathrm{ER}$, but to one of the lowest $(0.1 \%)$. Thus, we can assume that there is an inverse relationship between the audience engagement rate and the frequency of posts on the page in the social network Vkontakte and conclude that increasing the daily frequency of publications frequently leads to a decrease in the rate of involvement.

Since the denominator in the ER formula is essentially the number of subscribers to the social network, by matching these data we can try to determine whether there is a correlation between them. The data on the audience of the social network Vkontakte in the 3 leading Russian universities, recorded in 4 study periods from 2017 to 2020, are presented in Table 4 .

Table 4

\section{The audience of 3-top universities on VK}

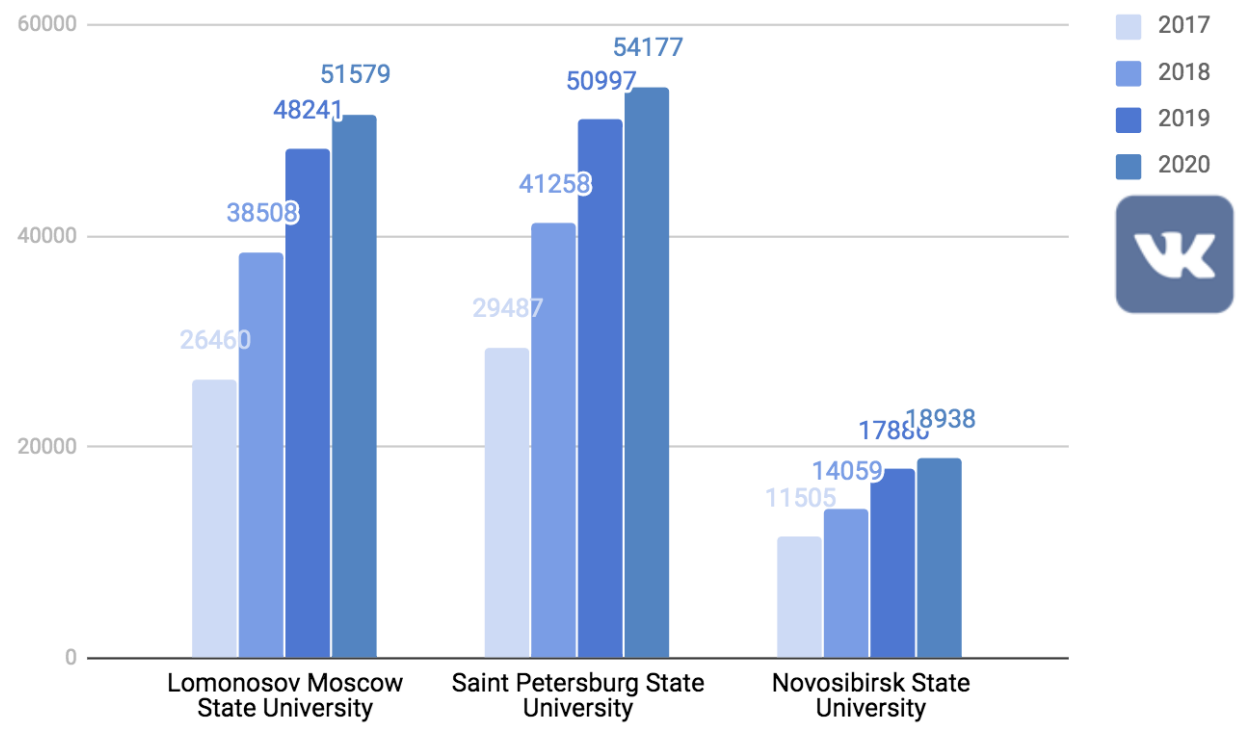


As with the total audience of all the social networks studied, the coverage of Vkontakte social network has consistently increased from 2017 to 2020. St. Petersburg State University has the largest number of subscribers to this social network in each survey period, with a peak value of 54177 subscribers. The maximum MSU's Vkontakte audience is slightly lower, at 51579 followers; the number of subscribers on the NSU page is much lower, at 18938.

Comparing these data with the data on the engagement rate, we can notice that the universities with a large number of subscribers (MSU and St. Petersburg State University) have on average lower involvement indicators. However, NSU's ER on the Vkontakte page in 2018 (0.1\%) was lower than that of St. Petersburg State University in the same year $(0.2 \%)$, but higher than that of Moscow State University (0), while NSU's audience in 2018 was 2-2.5 times lower. In addition, the number of subscribers gradually increased from 2017 to 2020, whereas the involvement rate did not decrease or increase consistently, but was chaotic. Therefore, regarding the Vkontakte social network, it cannot be said that the larger the audience, the smaller the ER of the social network. Rather, it is more difficult to involve a larger audience than a smaller one, which is shown by averages, but there is no proportional relationship between these data.

\section{Facebook}

As for the involvement of the audience of selected universities in the Facebook social network from 2017 to 2020 (Table 5), the record figure is again at NSU (2.3\% in 2020) and significantly ahead of other universities - the indicators of MSU and St. Petersburg State University do not reach even 1\%. At the same time, the highest indicator of NSU is already medium in terms of ER value, but it is only in 2020. In 2018 and 2019 NSU indicators are equal to zero - media promotion in social networks during the study period was not carried out at all. Analyzing ER on Facebook on the pages of Moscow State University and St. Petersburg State University, it can be noted that the last three years the figure has been growing, increasing annually by $0.1-0.2 \%$. The maximum index of St. Petersburg State University was recorded in 2017 (0.8\%), while that of Moscow State University - in 2020 (0.4\%). 
Table 5

The average engagement rate per post on Facebook in \%

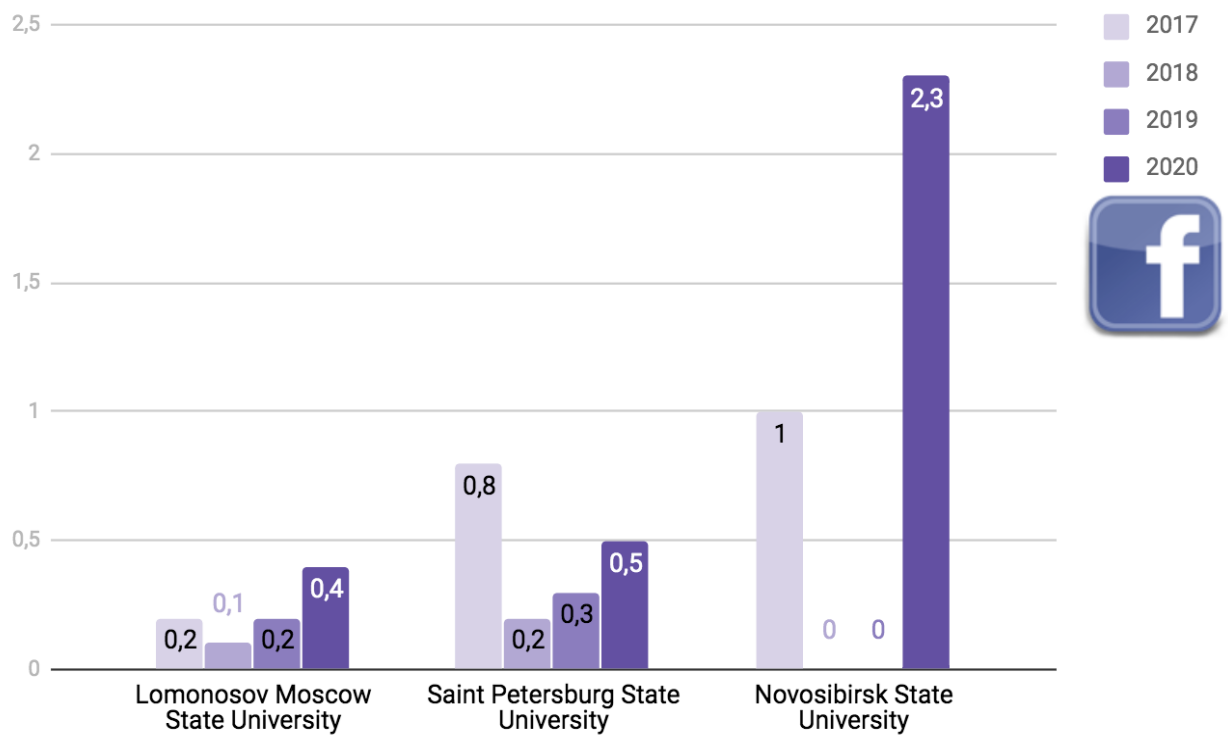

Comparing ER on Facebook (Table 5) with ER on Vkontakte (Table ), we can see that the record level of NSU's engagement rate in Facebook in 2020 stands out significantly from all other indicators of both social networks, reaching the average for the first time. All other figures are low, peaking at a maximum of $1 \%$ (NSU's Facebook page in 2017). For comparison, the average ER for 4 years can be calculated separately for each social network, and on Facebook $(0.5 \%)$ it is approximately $0.3 \%$ higher than in Vkontakte $(0.2 \%)$.

To analyze media communication practices on Facebook, the average frequency of daily publications was calculated by analogy with Vkontakte (Table 6). It can be seen that this social network is most actively used by MSU, which published from 1.4 to 3.7 posts per day in 2017-2020 - these are the highest rates among all the universities studied. On the Facebook page of St. Petersburg State University more than 1 post per day was never recorded for all 4 studied periods: the indicators vary relatively evenly from 0.5 to 0.7 daily posts. NSU Facebook had the highest index in 2017 (1.3), the next two years there were no publications in the account, and there were only 0.1 posts per day or about 3 publications per month in 2020. 
Table 6

\section{The average daily frequency of publications on Facebook}

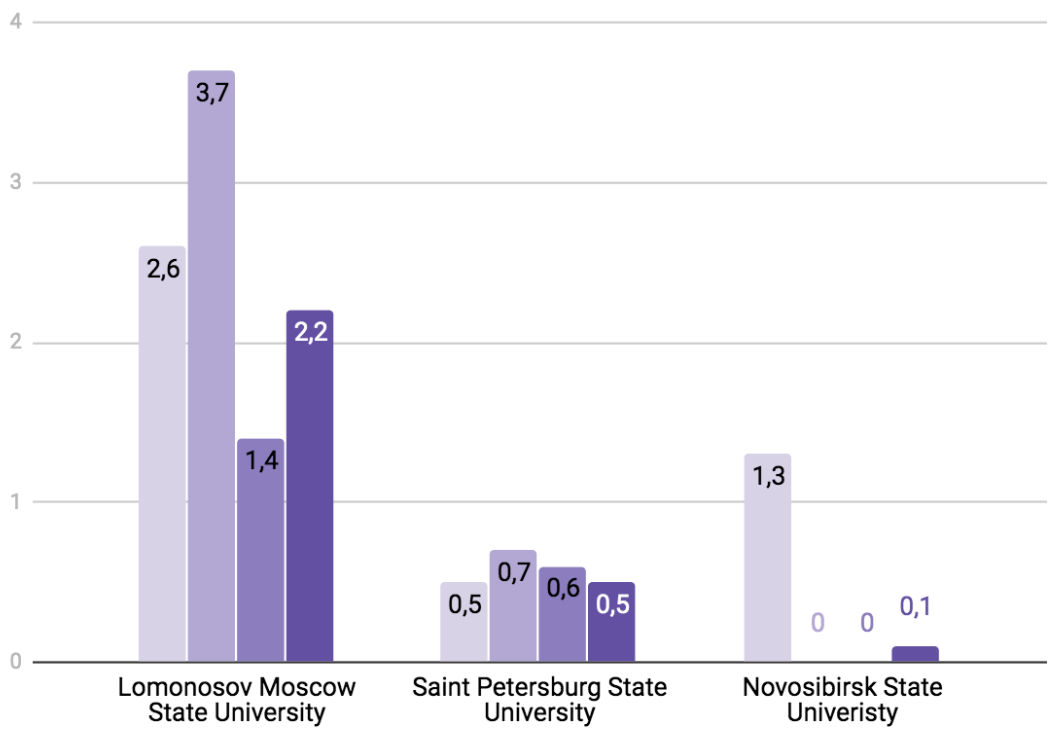

Hence, as well as on Vkontakte, the largest number of publications for all the studied periods on Facebook was made in the account of MSU, followed by the page of St. Petersburg State University. The least number of posts was made in the NSU's account. However, comparing the frequency of daily publications in general on two social networks, it can be noted that the Vkontakte page is more actively used among the universities: there were on average 2.5 publications per day during the study periods, while about 1.1 posts per day were published on Facebook.

If to examine how the Facebook engagement rate depends on the frequency of publications, the highest rate of audience involvement among all those demonstrated at NSU in $2020(2.3 \%)$ corresponds to the lowest frequency of daily publications (0.1), not taking into account those years when there were no publications in the NSU account at all. The lowest ER on NSU's Facebook for 4 years (1\% in 2017) corresponds to the highest frequency of publications (1.3). The lowest ER among the universities for the studied periods was shown in the MSU account ( $0.1 \%$ in 2018) and corresponds to the highest frequency of posts per day (3.7). Analyzing separately St. Petersburg State University indicators, one can also see that the highest ER (0.8\% in 2017) corresponds to the lowest frequency of daily publications (0.5), and the highest frequency (0.7 in 2018) is equal to the lowest ER (0.2\%). However, this correlation is shown 
not always. So, the lowest frequency of publications in the MSU Facebook account (1.4 in 2019) corresponds to the second largest ER (0.2\%). Nevertheless, as with the social network Vkontakte, it can be said that with increasing frequency of publications it is more difficult to achieve high engagement rate.

Reviewing the audience of the Facebook social network (Table 7), in general, it is possible to say that the number of subscribers of universities' official pages has consistently increased. The only exception is the account of NSU, which was created anew in 2020. The clear leader is MSU, the coverage of which has increased over 4 years by about 1.5 times from 38100 to 55760 people. It is interesting that the St. Petersburg State University account was created only in 2017 at the time of the research started and has 1332 subscribers in 4 years. The page of NSU also grew for the first three years, even though there was no media communication activity in 2018 and 2019.

Table 7

\section{The audience of 3-top universities on Facebook}

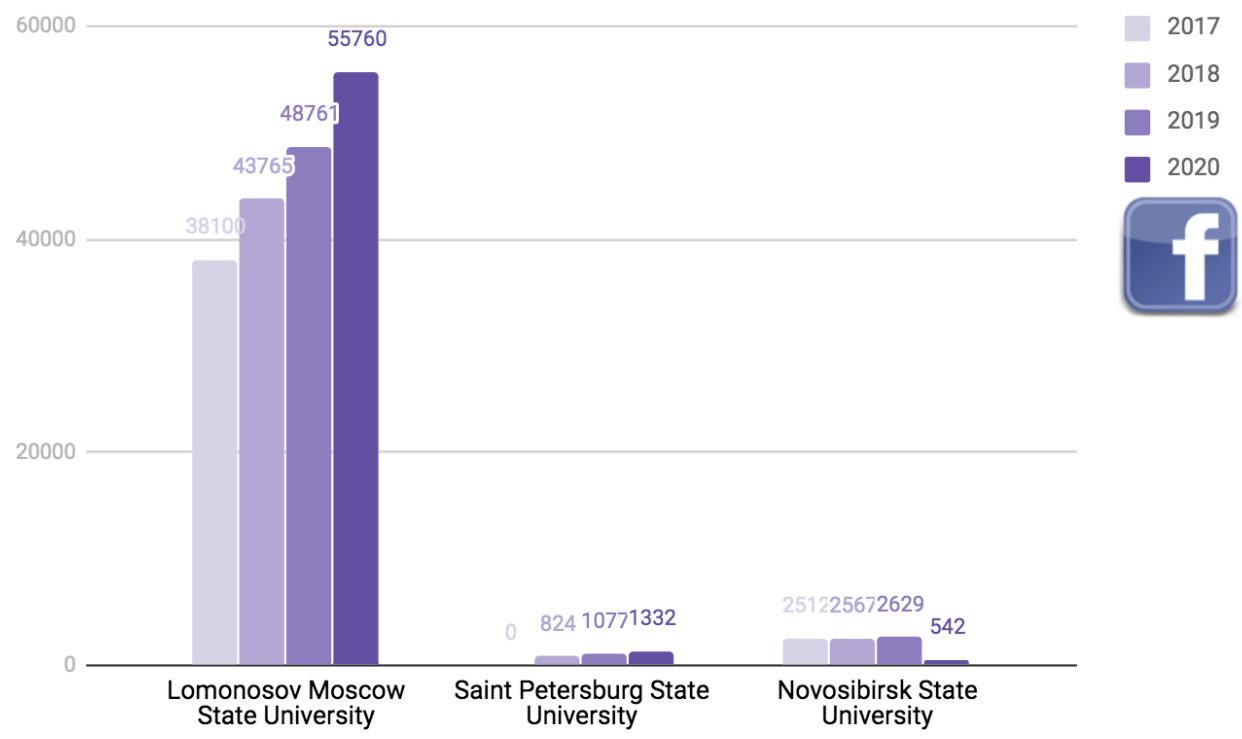

Comparing these data with the Facebook engagement rate (Table 5), it can be seen again that a university with a larger audience (MSU) has on average lower engagement rates. The highest involvement indicator among all in the NSU's account (2.3\% in 2020) corresponds to the lowest number of subscribers among all (542). 
However, as with the Vkontakte social network, the ER figures are distributed chaotically from period to period, unlike the growth dynamics of subscribers, which is mostly consistent. Again, it can be said that there is no direct correlation between ER and the number of the audience. Yet it is more difficult to engage and retain a large audience - this is demonstrated by low ER figures of MSU. Special attention should be paid to the Facebook account of St. Petersburg State University, which for all the periods studied had a growing, but the relatively low audience, low frequency of publications and low engagement rate. This may mean that the media communication activities on the Facebook page of St. Petersburg State University were inactive.

\section{Instagram}

The results of calculating the audience engagement in the Instagram social network in the studied periods 2017-2020 are presented in Table 8 and demonstrate that the audience of this social network was the most active. If we compare Instagram audience engagement with ER on Facebook and Vkontakte, on average Instagram users demonstrated $7.5 \%$ engagement, which is $7 \%$ more than on Facebook (0.5\%) and 7.3\% more than on Vkontakte $(0.2 \%)$.

Table 8

The average engagement rate per post on Instagram in \%

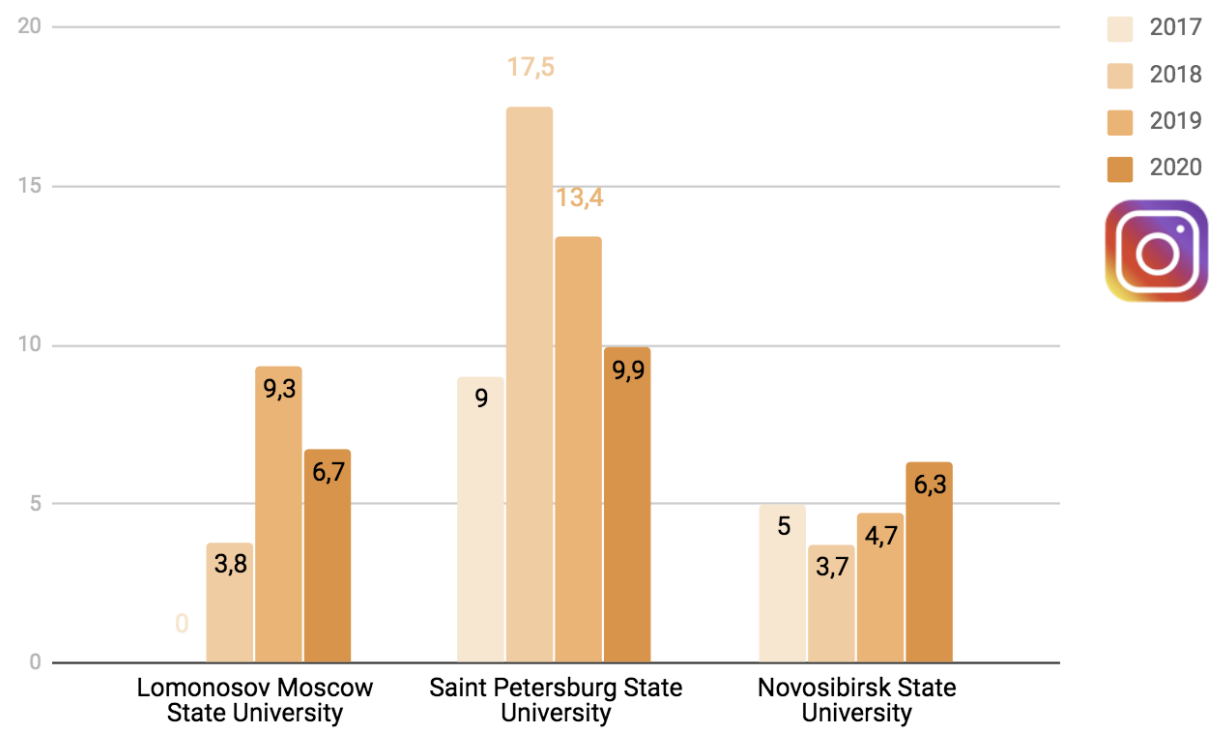


As a whole, all indicators of three higher education institutions for 4 years exceeded 3\%, which is a high result, 7 of them are above $6 \%$, which indicates a very high level of audience involvement. The exception is the zero index of MSU in 2017 when the page on Instagram was not available. The highest ER was recorded in the account of St. Petersburg State University in 2018 (17.5\%). In general, the St. Petersburg State University page had the highest ER for the periods under study - over $9 \%$.

Having reviewed the data about daily frequency of publications (Table 9), we can see that daily posts were made with the highest frequency in the Instagram account of NSU in 2017 (1.4). The index of St. Petersburg State University in 2019 was rounded to zero, which means one publication per month - this is the lowest frequency of daily publications among the universities studied. Compared to the media communication practices of universities in VKontakte and Facebook, publication activity in Instagram was the least frequent - an average of 0.4 posts per day, while in VKontakte and Facebook were on average 2.5 and 1.1 publications, respectively.

Table 9

The average daily frequency of publications on Instagram

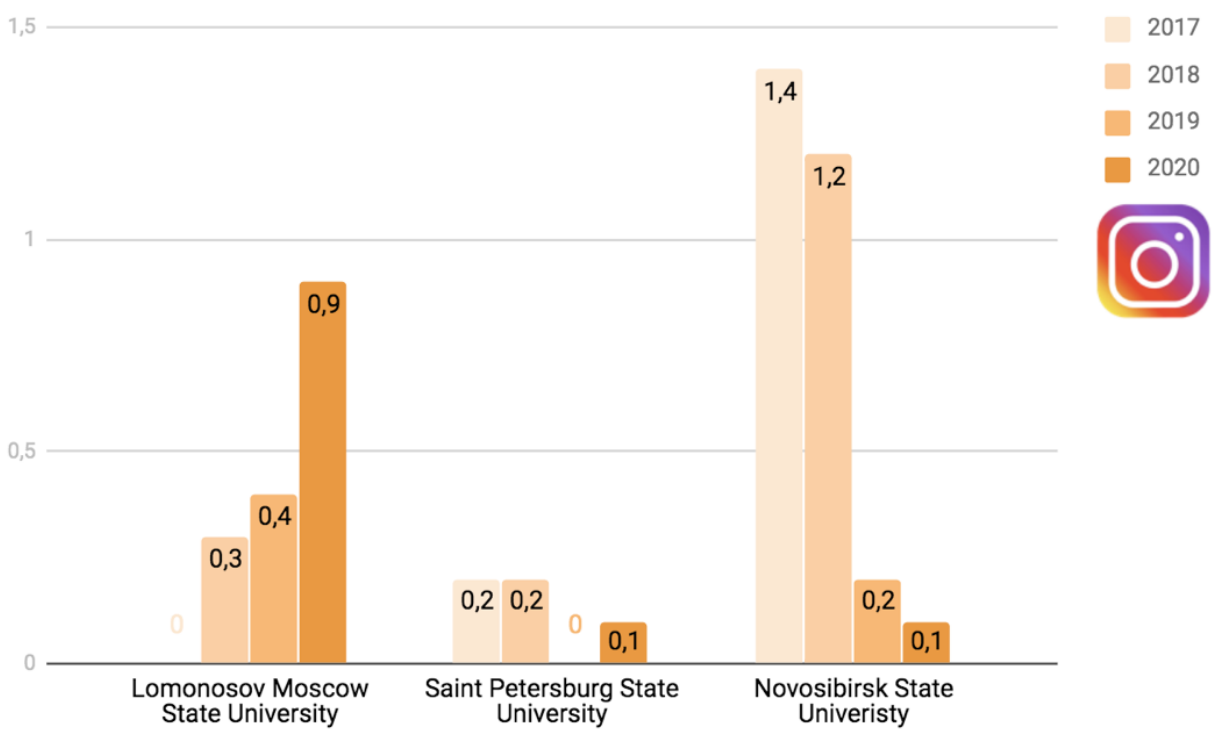


Comparing Instagram engagement rate in the study periods from 2017 to 2020 with the frequency of publications, it is possible to note that the correlation between these data is somewhat different than in Vkontakte and Facebook. Regardless of the number of publications per day, all universities demonstrated high audience involvement in all periods.

For instance, the St. Petersburg State University account was most effective $(17,5 \%)$ at the lowest frequency of daily publications (0-0.2), but there is no inverse correlation between these data. NSU's account had the highest ER $(6.3 \%)$ at the lowest frequency of daily publications (0.1). At the same time, the publication of more than 1 post per day in the NSU account did not lead to a clear decrease of ER - the indicators of 2017 (5\%), 2018 (3.7\%) and 2019 (4.7\%) were high, and 2020 - very high (6.3\%). In the Instagram account of MSU, there is also no inverse correlation between engagement rate and the frequency of daily publications, while the page did not publish more than 1 post per day, the engagement rate was high in 2018 (3.8\%) and very high in 2019 (9.3\%) and 2020 (6.7\%). Thus, it can be assumed that the Instagram audience of the surveyed universities depends more on other factors than the frequency of publications. In this case, we can determine the optimal frequency of publications for Instagram, in which engagement rate is high - about 1 or fewer publications per day.

Regarding the Instagram social network audience (Table 10), today the MSU account has the largest number of subscribers (13500). Besides, it has the highest dynamics of development: over 4 years MSU Instagram account has grown from 0 to 13500 subscribers, increasing by about 4.5 thousand people a year. Interestingly, unlike Vkontakte and Facebook, the Instagram audience at St. Petersburg State University has grown inconsistently - a sharp failure was recorded in 2019 when the number of subscribers fell from 6179 in 2018 to 4463 and then grew again to 9459 in 2020 . The growth of Instagram audience at NSU has the lowest dynamics among all of them - the number of subscribers has grown by 1700 people in 4 years. 
Table 10

\section{The audience of 3-top universities on Instagram}

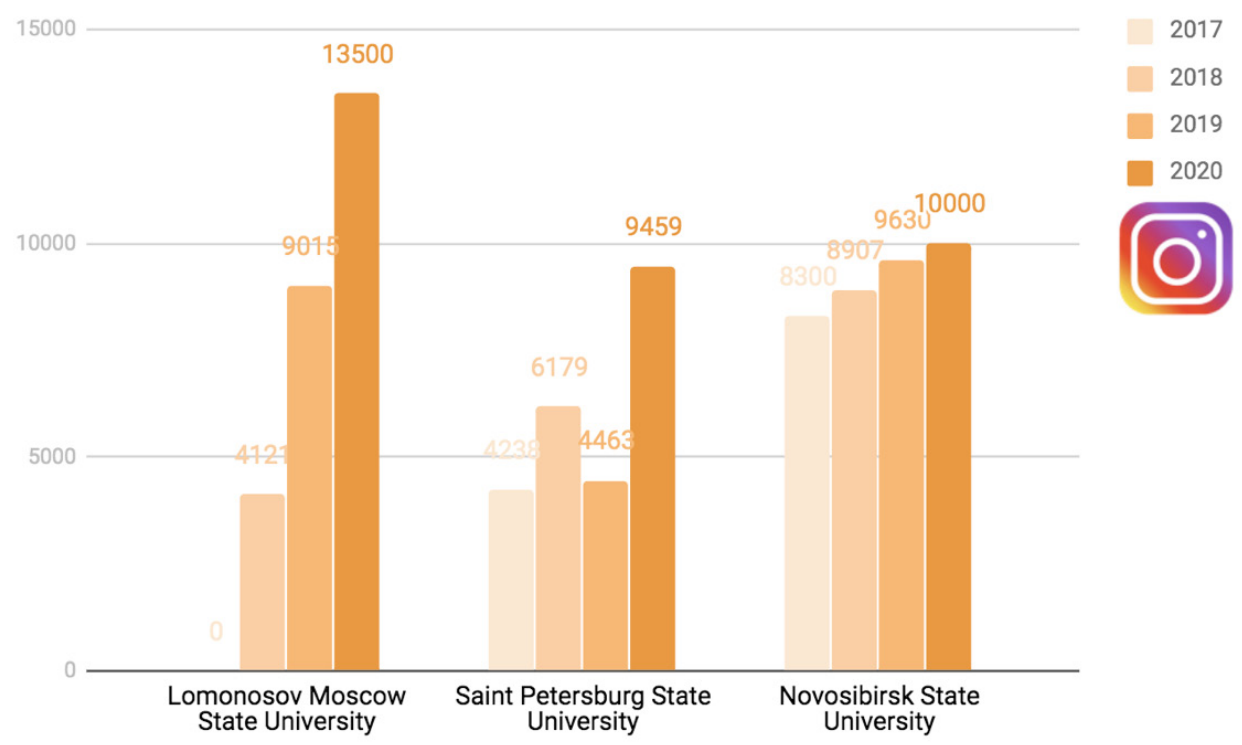

However, it can be ascertained that among the target audience the Instagram social network is more popular at NSU rather than at other universities, as in relation to the total audience of all social networks the percentage component of NSU audience is the highest: $34 \%$ of all NSU subscribers follow the Instagram account, while at MSU and St. Petersburg State University this indicator is $11 \%$ and $14.5 \%$ respectively.

Comparing the data on the number of subscribers with the audience involvement, we can see that in general, a university with the smallest audience (St. Petersburg State University) has a higher ER. However, this dependence is not clearly observed, the ER indicator is distributed chaotically, while, as in other social networks, the audience increases consistently from year to year, except for one failed period on the St. Petersburg State University page.

For example, the largest number of subscribers to NSU in $2020(10,000)$ corresponds to the highest ER (6.3\%), while the maximum number of subscribers to MSU in $2020(1,500)$ corresponds to the second largest ER $(6.7 \%)$. Therefore, in the social network Instagram, the engagement rate in the study does not show a clear dependence on the number of subscribers. 
Summing up the analysis of media communication activities of the top 3 Russian universities in social networks Facebook, Instagram and Vkontakte from 2017 to 2020, we can say that Vkontakte has the largest audience among subscribers and, therefore, is the most popular platform for media promotion in social networks. At the same time, Vkontakte has the lowest audience engagement, which can be explained both by the large audience and the frequency of daily publications, which is higher in Vkontakte than in other social networks.

Users are most active in the Instagram social network, where their involvement is much higher than in Vkontakte and Facebook. And although in contrast to Vkontakte among the universities studied Instagram has the smallest total audience and publications there are made less often than in other social networks, it cannot be said exactly that the larger the audience and the higher the frequency of publications, the less the engagement rate the Facebook audience of St. Petersburg State University and NSU was much smaller than in Instagram, and their ER was still much lower. Thus, high involvement in Instagram can be explained by the convenience of the platform, content and other factors and signal that this social network is perfectly suited to attract the target audience in the media communication activities of universities.

\section{Conclusion}

Social networks are the leader of the modern media system and represent great opportunities for media promotion of universities. The activities of universities in social networks create possibilities for fast and interactive communication, multimedia and modern familiar interface give the potential for increasing audience loyalty.

The results of the study confirm that the top 3 Russian universities are aware of the need and benefits of media communication in social networks and are actively developing their activities in them. We can note the positive dynamics of growth in the audience of accounts of almost all universities in social networks Facebook, Instagram and Vkontakte for 4 years from 2017 to 2020. MSU has the largest total audience, and the number of its subscribers is greater in all social networks except Vkontakte, where St. Petersburg State University is the leader in terms of audience coverage. From 2017 to 2020, Vkontakte remains the most popular social network among universities' target audience. 
To assess the effectiveness of media communication, the study calculated an average engagement rate in each period studied, the values of which indicate the success of media promotion. The results showed that audience involvement was always different - in each study period, the indicators were diverse and distributed chaotically without any particular trends from period to period. It can be noted that in general, the lowest ER was demonstrated on the social networks Vkontakte and Facebook, with the figures being mostly low by ER values. Only Instagram had high ER values, and they were significantly higher than in other social networks. This shows that users are actively involved in this social network and Instagram can be successfully used by universities for media communication activities.

Comparing the dynamics of development and efficiency of media and communication activities of the three leading universities of Russian higher education in the study period (2017-2020), we can say that the most successful media promotion in social networks among the universities studied is conducted by NSU. ER indicators of this university are on average higher than those of MSU and St. Petersburg State University, on Vkontakte and Facebook. Only in Instagram, the engagement rate in the account of NSU is lower than that of other universities, but these are high indicators, which allows us to talk about the successful media promotion of the university in the social network. However, NSU is the smallest university among the surveyed and has the smallest total audience in social networks, which demonstrates that it is more difficult for large universities with a larger audience to effectively conduct media and communication activities.

Having analyzed the frequency of daily publications in the accounts of the universities studied and its connection with the audience involvement, we cannot say that there is always an inverse correlation between these data. Nevertheless, it is obvious that a sharp increase in the number of posts per day often leads to a decrease in engagement rate. Thus, based on the data obtained, one can try to determine the optimal frequency of publications per day for the media communication activities of universities in social networks: it is no more than 2 posts per day.

All in all, the data obtained in the course of the study demonstrate that the volume of media communication in social networks is increasing, while Russian universities are trying to meet the modern features of media consumption and constantly changing standards of promotion in social networks. However, for media communication to be effective, quantitative audience growth is not enough; one should focus on qualitative indicators that most clearly reflect the active presence and response of subscribers. 


\section{References}

BUCCHI, M. \& TRENCH, B. (2018). Posobie po obschestvennyim svyazyam $v$ nauke i tehnologiyah [Routledge Handbook of Public Communication of Science and Technology]. Moscow, Alpina non-fiction.

DUNAS, D., TOLOKONNIKOVA, A., CHEREVKO, T. (2017). Aktualnyie konzeptualnyie podhody $\mathrm{k}$ rassmotreniyu processa mediapotreblenia [Current conceptual approaches to the process of young people's media consumption of online news]. Vestnik Moskovskogo universiteta. Seriya 10. Zhurnalistika, 5, pp. 30-50.

GOROKHOV, V. (2006). Korporativnyie kommunikazii: K probleme identifikazii public relations [Corporate communications: On the problem of identification of public relations]. Vestnik Moskovskogo universiteta. Seriya 10. Zhurnalistika, 5, pp. 94-101.

GOROKHOV, V., GUREEVA, A., SAMORODOVA, E. (2018). Korporativnyie kommunikazii rossiyskih vuzov v sozialnyih setyah [Corporate communications of Russian universitis in social networks]. Mediaalmanah, 6, pp. 36-41.

GUREEVA, A. (2017). Mediatizaziya nauchno-obrazovatelnoy deyatelnosti $\mathrm{v}$ internete: sait rossiyskogo vuza [Mediatization of scientific and educational activity on the internet: russian university websites]. Vestnik Moskovskogo universiteta. Seriya 10. Zhurnalistika, 3, pp. 58-88.

HAZELKORN, E. (2011). Rankings and the reshaping of higher education: The battle for worldclass excellence. Houndsmills, UK, Palgrave MacMillan.

JAAKONMÄKI, R., MÜLLER, O., VOM BROCKE, J. (2017). The impact of content, context, and creator on user engagement in social media marketing. Proceedings of the th Hawaii International Conference on System Sciences.

LAGUN, D. \& LALMAS, M. (2016). Understanding and measuring user engagement and attention in online news reading. Conference Paper, WSDM' 6, February 2 -25, San Francisco, CA, USA.

LUKINA, M. (2011). Internet-SMI: Teoriya i praktika [Internet media: Theory and oractice]. Moscow, AspectPress.

MERSEY, R., MALTHOUSE, E., CALDER, B. (2010). Engagement with online media. Journal of Media Business Studies, 7(2), pp. 39-56.

NAPOLI, P. M. (2014). Measuring media impact. An overview of the field. School of Communication and Information, Rutgers University.

NICIPORUC, T. (2014). Comparative analysis of the engagement rate on Facebook and Google Plus social networks. Proceedings of International Academic Conferences, International Institute of Social and Economic Sciences.

O'BRIEN, H. \& TOMS, E. (2008). What is user engagement? A conceptual framework for defining user engagement with technology. Journal of the American Society for Information Science and Technology, 59(6), pp. 938-955. 
VAN VUGHT, F. (2008). Mission diversity and reputation in higher education. Higher Education Policy, 21(2), pp. 151-174.

VARTANOVA, E. (2001). Novye problemy i novye prioritety cifrovoj epohi [New challenges and new priorities for the digital age]. Informacionnoe obshchestvo, 3. URL: http://emag.iis.ru/arc/infosoc/emag.nsf/BPA/ f38eef99ab1afe94c3256b5100279108

VARTANOVA, E. (2015). Sovremennye rossijskie issledovaniya SMI: obnovlenie teoreticheskih podhodov [Modern Russian media studies: updating theoretical approaches]. Vestnik Moskovskogo universiteta. Series 10: Zhurnalistika, 6, pp. 5-26.

VARTANOVA, E. (2017). K voprosu ob aktualizazii teorii zhurnalistiki i teorii SMI [On the problem of updating theory of journalism and the theory of the mass media]. Voprosy teorii i praktiki zhurnalistiki, 6(1), pp. 5-13.

VARTANOVA, E. \& GLADKOVA, A. (2019). New forms of the digital divide. In: J. Trappel, Digital media inequalities: Policies against divides, distrust and discrimination, Nordicom Goteborg. 